\title{
Linguistic Features of English for Science and Technology
}

\section{Olusegun Oladele Jegede}

Department of English and Literary Studies Lead City University, Ibadan, Nigeria

Email: jegedeolusegun@yahoo.com

\begin{abstract}
The goal of the study was to examine the linguistic features of English for Science and technology. To achieve the goal, content analytical method was adopted. This method was chosen because the sources of data for the study were two texts, one on science and the other on technology. The linguistic features of the contents of the texts were identified and categorised; the relevance of the linguistic features in the selected texts was determined; and the roles the linguistic features played in driving home the messages of science and technology texts were discussed. The findings revealed that texts for science and technology employ different levels of linguistic analysis such as graphology, lexis, syntax to drive home their messages. The study also found that the meaning and messages of the contents of science and technology texts rely heavily on these linguistic features. Thus, linguistic features are very relevant, and perform vital roles $n$ the construction of science and technology texts. The study concluded that the adept employment of linguistic features gives scientific and technological writings sound logic, accurate thoughts, and descriptive expressions.
\end{abstract}

Keywords: English for specific purposes; English for science and technology; language; communication

\section{Introduction}

Language is the ability possessed by humans to communicate with other humans using signs, such as words and movements. Because of its diverse types, language has become an important means of connecting between human beings. Therefore, language is mandatory and important in terms of communication (Surip and Mulyadi, 2019; Hartati, 2020; Syahrin, Sinar, Setia, and Nurlela, 2020). The importance of language in effective communication has been emphasised by several studies (Hariati, Pulungan, and Husein, 2020; Abd. Syakur, Sugirin, and Widiarni, 2020; Nuraflah, 2020; Poudel and Acharya, 2019). According to Eskandari (2020), language is an integral part of culture and society. Thus, like culture itself, language is a learned behaviour, which can be enhanced through direct or indirect contact. Language is needed by humans because language enables us to meet our need by communicating our needs to one another (Batubara, Lubis, and Kholil, 2020). As members of the community who are active in everyday life, people are very dependent on the use of language. In other words, where activities occur, there is a language activity involved.

Bahri (2020) observes that every word in a language has a meaning. When meaning is derived from a word, communication takes place. Syakur, Sugirin, Margana, Junining, and Sabat (2020) note that effective communication can only take place if the right language is used and the required skill is acquired in the field of communication. If the required skills are not learnt, there will be communication error (Wardah, 2020; Sudirman, Nasution, and Rosramadhana, 2020).

Dailami, Kholil, and Lubis (2020) note that all human activities must involve a communication process through which messages in the forms of ideas, opinions, intentions, etc. are delivered. Birgani and Jafari (2020) point out that that every participant in a communicative event has their ideologies which also affect their communication. 
Thus, as we have individual linguistic ideologies, we also have institutional linguistic ideologies. These unique ways of using language is what led to the growth and development of English for Specific Purposes.

Anna (2019) describes English for specific purposes (ESP) as a specific approach to English as a second or foreign language. ESP usually refers to teaching the English language to university students or people already in employment, with reference to the particular vocabulary and skills they need. As with any language taught for specific purposes, a given course of ESP will focus on one occupation or profession. Thus, we have Technical English, Scientific English, English for medical professionals, English for waiters, English for tourism, etc. This study focuses on the field of science and technology.

Science and Technology is a field with its own unique language. It has its own specialised English which is technically referred to as English for Science and Technology (EST). EST is the type of English used in scientific publications, papers, textbooks, technical reports and academic lectures, etc $(\mathrm{Li} \& \mathrm{Li}, 2015)$. It is used to describe physical and natural phenomena, their processes, properties, characteristics, laws and application in productive activities (Sageev and Romanowski, 2001; Kenneth, 2004). As an outcome of the rapid development of science and technology after World War II, EST initially emerged in the 1950s (Rao, 2014). Since the 1970s, together with the shift development of science and technology as well as the popularity of the English language, EST has developed into an important variety of modern English in many countries, as pointed out by Zhang (2008). Due to its main functions of statement, description, exposition, definition, classification, instruction, comparison, exemplification, inference and reasoning, EST has achieved its own language characteristics that contribute to the formal, concise, precise, impersonal and economical style of scientific documents. This paper explores the characteristics of EST through various examples at such language levels as graphology, lexis and syntax aiming at creating the awareness of such characteristics among stakeholders in science and technology so as to improve their communicative skills.

\section{Review of Literatures}

\subsection{English for Science and Technology (EST)}

According to Lowe (2009), EST is a style of writing as a result of the development of science and technology. It is characterized by soundness in logic and accuracy in thinking. This kind of writing is usually formal in style and serious in tone. It does not take artistic beauty of language as its goal. Instead, it tries to achieve clarity in logic and accuracy in meaning ( $\mathrm{Li} \& \mathrm{Li}, 2015)$. Thus, it has its own linguistic features, which are different from the literary English and other English styles. There are many prominent linguistic features at different levels of language. The features of EST are discussed in the following section based on different levels of linguistic analysis.

\section{a. Features of English for Science and Technology (EST) \\ 1. Graphological Features}

In EST, the writing form varies a little. It is used as a convenient and communicative medium to convey the latest information in science and technology and exchange academic achievements concerning this field. As a result, this kind of writing is formal in style. Only so, it can clearly communicate the information to the people who are interested in it. 


\section{a). Punctuation}

The punctuations can help the readers to have a better understanding of the sentence structures and the whole meanings the passages are going to convey. So the punctuations in EST are very beneficial to the readers when they are reading such texts. The question mark is barely used. Thus, it shows that the sentences in this kind of English style are quite long. Also, the sentences are not interrogative sentences but totally declarative sentences. As a result of these, the structures in EST are tightly organized and its subject matters are quite single. EST is used to convey scientific information, but not to exchange feelings, which the interrogative sentences, the exclamatory sentences and the imperative sentences are quite easily used to convey.

\section{b). Paragraphing}

In EST, the sentences are quite long, and in each sentence, there are a lot of words. This is because this kind of style aims to describe the scientific facts, explain the scientific phenomena, and conclude the scientific conceptions. It needs a certain number of words and sentences to communicate the information to the users. So, it has formed such sort of long sentences and a great many paragraphs.

\section{Lexical Features}

a). Use of Long and Big Words

In EST texts, long words are quite frequently used. These words are very suitable for English for science and technology because they can express the meaning in a more accurate way. These words are in accordance with the requirements of the scientific English that it tries to avoid the ambiguity in words or expressions.

\section{b). Use of Nominal Words}

Nominal words such as "motion, investigation, and separation" are used many times. Such kinds of words indicate the formality of the text, and make much information combined together closely coherently and logically. Science and technology is a formal and objective subject, which cannot use the ambiguous words. In other styles, verbs, adjectives, and some other words act as the grammatical components, while in EST, it is often the nominal words that are quite often used instead of the verbs and adjectives.

\section{c). Frequent Use of Technical Terms}

Technical terms are frequently used, among which are many words that come from the ordinary English style. However, in the domain of science and technology, they are used differently in meaning and have special meanings different from what we usually see and understand. So they could make the information and the content more scientific and well-knit.

\section{Syntactic Features}

a). Frequent Use of the Passive Voice

In EST passages, the passive voices are frequently used. In physics, chemistry, and engineering texts, one third of all finite verbs are passive voice. In EST, passive voice not only occurs quiet frequently but also becomes one of the important devices to make the text objective and standard. Since the scientific style attaches more importance to facts, phenomena, or processes, passive voice is employed to stress the objects and the contents of the sentences.

\section{b). Frequent Use of Declarative Sentences}

Coherence in logic, clarity and fluency in expression are typical of the scientific English. Therefore, the declarative sentences have a high proportion in EST. The author of 
EST does not express his own feelings, because EST tries to avoid subjective opinions or evaluations. The agents of the actions could be anybody in many cases. Besides, the focus of the text is not on the people or the agents but on the objective phenomena and the information itself.

\section{c). Frequent Use of the Present Tense}

The scientific disciplines and phenomena are not restricted by time. For this reason, the present tense appears almost throughout EST texts. When the word 'will' is used, it is used for judging or guessing but not for the future tense.

d). Frequent Use of Long Sentences and Complex Sentences

According to the statistic research conducted by Yuan (1991), the average simple sentence in all English styles includes 17.8 words but in most EST passages, the average word in each sentence is 24.4. This indicates that the sentence length in EST is longer by far than that in other types of English styles. EST is a functional style. It is used to express complicated thoughts and logical relationships. As a result of these, long sentences are frequently put into use. Also, the majority of the sentences found in EST passages are complex sentences. The relative pronouns 'which' and 'that' appear often in the scientific and technology texts. In order to enhance the objectivity and the accuracy of the information, such sentences are frequently used in the passage.

e). Use of Prepositional Phrases

EST passages also have quite a lot of prepositional phrases, especially the preposition 'of. The prepositional phrases can make the sentences organized more closely and the structures understood easily.

\section{Research Methods}

The study is descriptive in its approach. Two texts were selected for analysis - a science text (How Lizards Can Shed Their Tail When Predators Attack) and a technology text (How Space Technology Benefits the Earth). The science text was tagged 'sci text' while the technology text was tagged 'tech text'. The features of English for Science and Techmology were identified in the texts and their roles in the texts were interpreted. The relevance of the features to the messages of the texts was also determined.

\section{Discussion}

In the following excerpts, the features of English for Science and Technology (EST) are analysed at different levels of linguistic analysis - Graphology, Lexis and Syntax.

\subsection{Graphological Analysis} examined.

At this level, the use of punctuation marks, paragraphs, capitalisation and figures are

\section{a. Punctuation}

\section{Extract 1}

"The only predators that truly matter are vipers," said U-M vertebrate ecologist Johannes Foufopoulos, co-author of a study published online this week in the journal Evolution. (Sci Text) 


\section{Extract 2}

But when a viper bares its fangs and strikes, even glancing contact with the lizard's tail can inject a lethal dose of venom. In that case, the ability to shed a tail within seconds-before venom reaches the lizard's vital organs_-becomes a life-or-death matter. (Sci Text)

\section{Extract 3}

Tail-shedding, known to scientists as caudal autotomy, is a common anti-predator defense among lizards. When attacked, many lizards jettison the wriggling appendage and flee. The predator often feasts on the tail while the lucky lizard scurries to safety. Later, the lizard simply grows a new tail. (Sci Tech)

\section{Extract 4}

The worst-case scenario is that a series of accidental or deliberate collisions in orbit produces an exponential increase in debris, leading to an inability to operate in space-the so-called "Kessler Syndrome." (Tech Text)

From the extracts above, we will observe that the punctuation marks help the readers to have a better understanding of the sentence structures and the whole meanings the texts are conveying. In the texts, the comma, the dash, the inverted comma, the quotation marks are used more frequently than in other types of writings. The question mark is seldom used. Thus, the sentences are not interrogative sentences, exclamatory sentences or imperative sentences, but primarily declarative sentences. As a result of these, the structures in EST are tightly organized and its subject matters are quite single.

\section{b. Paragraphing}

\section{Extract 1}

Mainland Greece and the thousands of offshore islands of the Aegean are an ideal place to study how evolution shapes isolated animal populations, with each group adapting to conditions peculiar to its home island. The situation is reminiscent of Darwin's study of finch-beak variation on the Galapagos Islands. (Sci Text)

\section{Extract 2}

The U-M-led team decided to test the long-held predator-pressure idea using a clever combination of laboratory experiments and field measurements made in mainland Greece and multiple offshore Aegean Sea islands inhabited by different combinations of predators. (Sci Text)

\section{Extract 3}

Earth observation provides information and support for agricultural production, fisheries management, freshwater management, and forestry management, as well as monitoring for harmful activities, such as illegal logging, animal poaching, fires, and environmentally pernicious mining. (Tech Text)

\section{Extract 4}

Global PNT satellite systems, which can pinpoint a location to within a few meters (or much better) anywhere on the Earth's surface, have enhanced land and sea navigation, logistics (including ride-hailing services that are transforming personal transportation), precision agriculture, military operations, electrical grids, and many other industrial and societal aspects of Earth life. Space-based location services built into mobile phones and used by applications on mobile phones ranging from maps to dating services have become 
so intertwined with modern life that their abrupt cessation would be viewed as catastrophic. (Tech Text).

In the texts, the paragraphs have long sentences and a lot of words. This is because ST texts aim to describe scientific facts, explain scientific phenomena, and conclude the scientific conceptions. It needs a certain number of words and sentences to communicate the information to the users. So, it has formed such sort of long sentences and a great many paragraphs.

\section{c. Capitalisation}

\section{Extract 1}

U-M-led team decided to test the long-held predator-pressure idea (UM - University of Michigan) (Sci Text)

\section{Extract 2}

Beyond economics, a healthy space sector will continue to inspire people young and old about new frontiers, discoveries, and technologies, and foster interest in STEAM (science, technology, engineering, art, and math) (Tech Text)

\section{Extract 3}

Another company, Star Technology and Research Corporation, is developing a non-fuel consuming, electrodynamic debris eliminator (EDDE),... (Tech Text)

\section{Extract 4}

Global PNT (Positioning, Navigation, and Timing) satellite systems, which can pinpoint a location to within a few meters (or much better) anywhere on the Earth's surface, have enhanced land and sea navigation, logistics... (Tech Text)

\section{Extract 5}

One reason for this recent explosion in space-related activity is the plunging cost of launch to low Earth orbit (LEO). (Tech Text)

\section{Extract 6}

... construction of the International Space Station (ISS),... (Tech Text)

\section{Extract 7}

The principle of space solar power (SSP) is to capture this abundant sunlight ... (Tech Text)

As revealed in the extracts above, ST texts use a lot of capitalisations and abbreviations which often helps to save space, making the presentation more concise and compact. The use of capitalisation also helps to make concepts more prominent, more closely linked to the information in the texts and the description more vivid.

\section{d. Use of Figures}

\section{Extract 1}

... researchers used calipers to gently pinch lizards' tails with a standardized level of pressure for 15 seconds. (Sci Text) 


\section{Extract 2}

The study involved more than 200 insect-eating lizards from 15 species, most measuring 5 to 8 inches from snout to tail-tip. (Sci Text)

\section{Extract 3}

... the presence or absence of various types of lizard predators at the study's 10 collecting sites. (Sci Text)

\section{Extract 4}

Although no one can say exactly how many lives are saved every year, it is worthwhile to note that, in 1900, a hurricane hit Galveston, Texas, killing 6,000 to 12,000 people because they had no warning. (Tech Text)

\section{Extract 5}

Supersonic air transport dates back to the Concorde in the 1970s... (Tech Text)

\section{Extract 6}

Some are using suborbital rocket technology that affords a few minutes of weightlessness about 100 kilometres above the surface... (Tech Text)

\section{Extract 7}

A recent survey indicated that more than 60 percent of Americans would do so ... (Tech Text)

The roles of figures are similar to those of capitalisations in that they help to save space, making the presentation more concise and compact. The use of figures also make scientific writings objective because they help to present the actual frequencies of the occurrences of certain phenomenon. Figures also help to make concepts or the findings more prominent, more closely linked to the information in the texts.

\subsection{Lexical Analysis}

\section{a. Use of Long or Compound Words}

\section{Extract 1}

... lizards that have lost this capacity are ill-equipped to defend themselves and quickly succumb to invasive snakes. (Sci Text)

\section{Extract 2}

Today, some of the Aegean islands are viper-free. (Sci Text)

\section{Extract 3}

Tail-shedding, known to scientists as caudal autotomy, is a common anti-predator defense among lizards. (Sci Text)

\section{Extract 4}

As the number of local lizard-eaters rises, so does the need for this effective defense mechanism. (Sci Text)

\section{Extract 5}

The study involved more than 200 insect-eating lizards from 15 species, most measuring 5 to 8 inches from snout to tail-tip. (Sci Text) 


\section{Extract 6}

The predator-pressure hypothesis, while generally true, comes with an unexpected twist: Not all predators are created equal. (Sci Text)

\section{Extract 7}

Cross-border business-to-business relationships also serve the same purpose. (Tech Text)

\section{Extract 8}

... power can be beamed to virtually any location on Earth within line-of-sight of the satellite. (Tech Text)

\section{Extract 9}

... to remove the burden of Earth-based electricity systems to power them. (Tech Text)

In EST texts, long or compound words are quite frequently used, such as Earth-based, line-of-sight, cross-border business-to-business, predator-pressure, insect-eating, lizard-eaters, tail-shedding, etc. These words are very suitable for the English for science and technology, because they can express the meaning of terms or concepts in an accurate way. These words are in accordance with the requirements of the scientific English that it tries to avoid ambiguity in words or expressions.

\section{b. Use of Nominal Words}

\section{Extract 1}

"In the Aegean, vipers are specialized lizard predators," ... "So it makes sense, in retrospect, that the lizards' primary defense would be aimed against their main enemy, the viper. (Sci Text)

\section{Extract 2}

... lizards that have lost this capacity are ill-equipped to defend themselves and quickly succumb to invasive snakes. (Sci Text)

\section{Extract 3}

... the ability to shed a tail within seconds-before venom reaches the lizard's vital organs-becomes a life-or-death matter. (Sci Text)

\section{Extract 4}

However, tail loss carries long-term costs, including impaired mobility, lower social status and slower growth rates. (Sci Text)

\section{Extract 5}

Tail-shedding, known to scientists as caudal autotomy, is a common anti-predator defense among lizards. (Sci Text)

\section{Extract 6}

As the number of local lizard-eaters rises, so does the need for this effective defense mechanism. (Sci Text)

\section{Extract 7}

The study involved more than 200 insect-eating lizards from 15 species, most measuring 5 to 8 inches from snout to tail-tip. (Sci Text) 


\section{Extract 8}

Nominal Words - The U-M-led team decided to test the long-held predator-pressure idea ... (Sci Text)

\section{Extract 9}

In March, the US announced an accelerated schedule to permanently return humans to the Moon in 2024. (Tech Text)

\section{Extract 10}

Space communication capabilities positively impact almost every aspect of human civilization. (Tech Text)

\section{Extract 11}

An early application could focus on supplying power to isolated communities or for disaster relief. (Tech Text)

\section{Extract 12}

Satellite technologies have already revolutionized banking and finance, navigation, and everyday communications ... (Tech Text)

Nominal words used in the texts indicate the formality of the text, and make much information combine together closely, coherently and logically. Science and technology is a formal and objective subject, which cannot use ambiguous words. In EST, it is often the nominal words that are quite often used instead of the verbs and adjectives.

\section{c. Use of Technical Terms}

\section{Extract 1}

The ease with which lizards shed their tails varies from species to species and from place to place. ... so does the need for this effective defense mechanism. (Sci Text)

\section{Extract 2}

"The only predators that truly matter are vipers," said U-M vertebrate ... (Sci Text)

\section{Extract 3}

However, tail loss carries long-term costs, including impaired mobility, lower social status and slower growth rates. So from an evolutionary perspective ... (Sci Text)

\section{Extract 4}

Today, those predators include mammals such as foxes and jackals,... (Sci Text)

\section{Extract 5}

When attacked, many lizards jettison the wriggling appendage and flee.

(Sci Text)

\section{Extract 6}

Technical Terms - The answer, in a word: Venom. (Sci Text)

\section{Extract 7}

Today, data centres are often being located in cold climates to take advantage of lower operating temperatures and cooling loads... (Tech Text) 


\section{Extract 8}

Known in climate change circles as "solar geoengineering" or "solar radiation management" (SRM), most approaches rely on injection of aerosol particles into the stratosphere. (Tech Text)

\section{Extract 9}

Low gravity is to be distinguished from zero gravity ... (Tech Text)

In the domain of science and technology, as seen in the texts, technical terms are used differently and have special meanings different from what we usually see and understand. So they usually make the information and the content of ST texts more scientific and well-knit.

\subsection{Syntactic Analysis}

\section{a. Frequent Use of the Passive Voice}

\section{Extract 1}

Funding for the study was provided by U-M's School of Natural Resources and Environment and the U-M Modern Greek Program.

\section{Extract 2}

Laboratory autotomy rates for each species were expressed as the fraction of lizards that shed their tails during this procedure. (Sci Text)

\section{Extract 3}

For more than a century, biologists have suspected that this variation is controlled mainly by predator pressure (Sci Text)

\section{Extract 4}

Not all predators are created equal. (Sci Text)

\section{Extract 5}

This result is perhaps best explained by the peculiarities of viper attacks, Foufopoulos said.

\section{Extract 6}

... the study was conducted in the Mediterranean region (Sci Text)

\section{Extract 7}

The lunar farside is protected by the Moon from electromagnetic emissions coming from the Earth... (Tech Text)

In the EST texts, the passive voice is frequently used. In the texts, the passive voice occurs quiet frequently in order to make the text objective and standard. Since the scientific style attaches more importance to facts, phenomena, or processes, and also it is not interested in the doers of the action but in results achieved, passive voice, is therefore employed to stress the objects and the contents of the sentences.

\section{b. Frequent Use of Declarative Sentences}

\section{Extract 1}

University of Michigan ecologists and their colleagues have answered a question that has puzzled biologists for more than a century. (Sci Text) 


\section{Extract 2}

Tail-shedding, known to scientists as caudal autotomy, is a common anti-predator defense among lizards. (Sci Text)

\section{Extract 3}

The predator often feasts on the tail while the lucky lizard scurries to safety. Later, the lizard simply grows a new tail. (Sci Text)

\section{Extract 4}

Many other nations are also focused on a return to the Moon. (Tech Text)

\section{Extract 5}

Falcon Heavy now boasts the lowest cost in the industry, with a base price of $\$ 1,655$ per kilogram to LEO. (Tech Text)

\section{Extract 6}

$\ldots$ it is worthwhile to note that, in 1900, a hurricane hit Galveston, Texas, killing 6,000 to 12,000 people because they had no warning. (Tech Text)

The selected EST texts use a high proportion of declarative sentences to ensure coherence in logic, clarity and fluency in expression. Such declarative expressions enable EST texts to avoid subjective opinions or evaluations. The agents of the actions could be anybody in many cases. Besides, the focus of the text is not on the people or the agents but on the objective phenomena and the information itself.

\section{c. Frequent Use of Present Tense}

\section{Extract 1}

"In the Aegean, vipers are specialized lizard predators,"... (Sci Text)

\section{Extract 2}

"The only predators that truly matter are vipers," (Sci Text)

\section{Extract 3}

But when a viper bares its fangs and strikes, even glancing contact with the lizard's tail can inject a lethal dose of venom.

\section{Extract 4}

The ability to shed a tail within seconds ... becomes a life-or-death matter. (Sci Text)

\section{Extract 5}

The predator-pressure hypothesis comes with an unexpected twist. (Sci Text)

\section{Extract 6}

A prime example is sourcing rocket propellant in space ... (Tech Text)

\section{Extract 7}

Satellites used for weather prediction almost certainly save thousands of lives each year by giving the public storm warnings. (Tech Text) 


\section{Extract 8}

Earth observing satellites also monitor greenhouse gases and other crucial climate indicators. (Tech Text)

The scientific disciplines and phenomena are not restricted by time. For this reason, the present tense appears almost throughout EST passages. Where the word 'will' is used, it is used for judging or guessing but not as a future tense.

\section{d. Frequent Use of Long and Complex Sentences}

\section{Extract 1}

Lead author of the Evolution paper was SNRE's Panagiotis Pafilis. The co-authors are Foufopoulos, Nikolaos Poulakakis of Yale University, Petros Lymberakis of the Natural History Museum of Crete and Efstratios Valakos of the University of Athens. (Sci Text)

\section{Extract 2}

When lizards live alongside lots of creatures eager to devour them, they're more likely to evolve the ability to shed their tails easily, because this trait enables them to survive long enough to reproduce and pass their genes to the next generation. (Sci Text)

\section{Extract 3}

The U-M-led team decided to test the long-held predator-pressure idea using a clever combination of laboratory experiments and field measurements made in mainland Greece and multiple offshore Aegean Sea islands inhabited by different combinations of predators. (Sci Text)

\section{Extract 4}

With an explosion of more than 2,000 commercial space companies, including those building communications satellites, orbital launch vehicles, rovers for the Moon and Mars, orbital habitats, space manufacturing platforms, and space greenhouses, the world's commercial space capabilities are quickly expanding beyond our satellite industry, which over the last year already brought in more than $\$ 277$ billion in global revenues. (Tech Text)

\section{Extract 5}

Aside from long-standing commercial satellite services, our expanding space industry, in the process of moving beyond exclusive dependence on limited government budgets and cost-plus contracting, brings with it economic opportunities, not only to those working directly in the space sector but also to non-space actors, including many small businesses. (Tech Text)

The long and complex sentences in the texts are used to express the complicated thoughts and logical relationships expressed in the texts. The majority of the sentences found in EST passages are complex sentences. The sentences are usually long and complete. Therefore, the sentence patterns vary a little. The relative pronouns "which" and "that" appear numerously in the scientific and technical passages. In order to enhance the objectivity and the accuracy of the information, such sentences are frequently used in the passage.

\section{e. Use of Prepositional Phrases}

\section{Extract 1}

Tail-shedding, $\ldots$ is a common anti-predator defense among lizards. 


\section{Extract 2}

The predator often feasts on the tail while the lucky lizard scurries to safety. Later, the lizard simply grows a new tail. (Sci Text)

\section{Extract 3}

The ease with which lizards shed their tails varies from species to species and from place to place.

\section{Extract 4}

Historically, costs have averaged more than $\$ 10,000$ per kilogram of launched mass. (Tech Text)

\section{Extract 5}

... helping lower the cost of deep space operations. Other plentiful materials such as iron and other metals will be valuable for in-space construction. (Tech Text)

\section{Extract 6}

Other technologies, such as manufacturing materials in space from resources found on the Moon, Mars, or asteroids, could further improve the economics of space activities by dramatically reducing the amount, and hence cost, of material launched from Earth ... (Tech Text)

The EST texts also have quite a lot of prepositional phrases, especially the prepositions in..., of..., on..., for..., to..., by..., . The prepositional phrases make the sentences better organized and the structures are understood easily.

\section{f. Replacement of Verb Phrases by Verbs \\ Extract 1}

Over the millennia, sea levels rose and thousands of Aegean islands formed. (Sci Text)

\section{Extract 2}

When attacked, many lizards jettison the wriggling appendage and flee. (Sci Text)

\section{Extract 3}

The only strong signal that emerged from the study was the link to vipers. (Sci Text)

\section{Extract 4}

The study involved more than 200 insect-eating lizards from 15 species, most measuring 5 to 8 inches from snout to tail-tip. (Sci Text)

\section{Extract 5}

... the researchers combined field observations and laboratory measurements. (Sci Text)

\section{Extract 6}

What is the main factor that determines a lizard's ability to shed its tail when predators attack? (Sci Text)

\section{Extract 7}

When lizards live alongside lots of creatures eager to devour them, they're more likely to evolve the ability to shed their tails easily, ... (Sci Text) 
A large number of English verbs and their corresponding verb phrases share the same meaning in a certain language context. Comparatively, single verbs are more more formal while verb phrases are more colloquial and more widely used in spoken English. In order to avoid the ambiguity or colloquialism, and to achieve the formality and preciseness of science and technology texts, formal verbs such as evolve, shed, combined, involved, emerged, jettison, and formed are used instead of verb phrases in selected texts.

\section{Conclusion}

It is obvious from the study that scientific English is somewhat different from general English. As the study shows, EST has its own unique features. Thus, it is very important for stakeholders in science and technology to understand the characteristics and use them in their writings. However, not all the features are exclusive to science and technology texts. Some of them can also be found in other genres or fields.

The knowledge of EST is necessary for teachers in the field of science and technology because it will help them with the linguistic competence required of them on their jobs. The findings of the study provide useful and practical information to science, engineering, and technical institutions to improve the competencies of the English teachers so that the students can benefit while accomplishing their language and professional needs. Learning about academic ways of using language is one way of helping students participate in new ways of learning.

\section{References}

Abd. Syakur, Sugirin, Widiarni (2020). The Effectiveness of English Learning Media through Google Classroom in Higher Education. Britain International of Linguistics, Arts and Education (BIoLAE), 2, (1), 475-483.

Anna, T. (2019). Towards Various Aspects of Teaching Language for Specific Purposes at Higher Education Institutions. Journal of Foreign Language Education and Technology: 111-126.

Bahri, S. (2020). The Different Types of Words Meaning in Minangkabau Proverbs: A Stylistics Approach. Budapest International Research and Critics in Linguistics and Education (BirLE), 3(2), 695-705.

Batubara, A. K., Lubis, S. and Kholil, S. (2020). Parents' Communication Strategies in Building Internet Media Literacy for Youth in Muslim Family in Tanjung Mulia Medan Deli. Britain International Journal of Humanties and Social Sciences (BIoHS), 2, (1), 45-54.

Birgani, S. Z. and Jafari, M. (2020). A Gramscian Study of Ideology and Hegemony in Amiri Baraka play: The Dutchman. Budapest International Research and Critics InstituteJournal (BIRCI-Journal), 3(2), 729-737.

Dailami, Kholil, S., and Lubis, L. (2020). The Communication Patterns of Leadership in Improving Work Ethic of Lecturer and Staff in Asahan University (Islamic Communication Perspective). Budapest International Research and Critics InstituteJournal (BIRCI-Journal), 3(1), 469-476.

Eskandari, S. (2020). Language Discourse in James Joyce's Short Stories The Grace and The Araby: A Cultural Studies. Budapest International Research and Critics in Linguistics and Education (BirLE), 3(1), 411-420.

Hariati, P., Pulungan, A. H. and Husein, R. (2020). Illocutionary Acts in Jack Ma's Inspiring Speech in His Graduation at The University of Hongkong. Britain International of Linguistics, Arts and Education (BIoLAE), 2(1), 384-394. 
Hartati, T (2020). The Role of Human Relations in Increasing Employee Performance. Budapest International Research and Critics Institute-Journal (BIRCI-Journal), 3(1), 127-133.

Kenneth, C. (2004). Rethinking an engineer's education. Electronic Engineering Times, 1315, 59.

Li \& Li (2015). Characteristics of English for Science and Technology. 2015 International Conference on Humanities and Social Science Research (ICHSSR 2015), Information Communication Training Department, Technology College, State Grid of China.

Lowe, I. (2009). Characteristics of the language of science. ESP today: a practitioner's guide. Prentice Hall, UK.

Nuraflah, C. A. (2020). The Communication Strategy of Government in Bulu Cina Village towards Prosperous Village. Britain International of Humanities and Social Sciences (BIoHS), 2(2), 374-380.

Poudel, K. K. and Acharya, H. P. (2019). Context in Oral Communication: What would be the Pedagogic Implications? Budapest International Research and Critics in Linguistics and Education (BirLE), 2(4), 01-12.

Rao, C. S. (2014). English For Science And Technology: A Learner Centered Approach. English for Specific Purposes World, 42(15) 1-11.

Richards, J. \& Rodgers, T. (2001). Approaches and methods in language teaching: a description and analysis. Cambridge: Cambridge University Press.

Sageev, P. and Romanowski, C. J. (2001). A message from recent engineering graduates in the workplace: Results of a survey on Technical Communication skills, Journal of Engineering Education, October, 685-693.

Sudirman, Nasution, I. H. and Rosramadhana (2020). The Efforts of Housewife to Improve Communication Patterns in the Family at Padang Lawas Regency, North Sumatera. Budapest International Research and Critics in Linguistics and Education (BirLE), 3(1), 324-329.

Surip M. and Mulyadi (2019). Conceptual Metaphor in Human Communication. Budapest International Research and Critics in Linguistics and Education (BirLE), 2(4), 120-132.

Syahrin, E., Sinar, T. S., Setia, E. and Nurlela (2020). Polite Requests of Indonesian Learners of FLE and French Native Speakers: An Interlanguage Study. Budapest International Research and Critics Institute-Journal (BIRCI-Journal), 3(1), 216-226.

Syakur, Sugirin, Margana, Junining, E, Sabat, Y. (2020). Improving English Language Speaking Skills Using "Absyak" On-Line Learning Model for Second Semester in Higher Education. Budapest International Research and Critics in Linguistics and Education (BirLE), 3(2), 684-694.

Wardah, J. (2020). Grammatical Interference in the Aceh Language in the Use of Indonesian Writing Variety of 7th Grade Students of Junior High School 1 Indrapuri Aceh Besar District and Their Utilization as Teaching Materials in Learning to Write Narrative Texts. Budapest International Research and Critics in Linguistics and Education (BirLE), 3(1), 478-486.

Zhang, S. W. (2008). English for Science and Technology, Xian: Xian Electronic Science \& Technology, University Press , 2008. 